\title{
C-13 Chemical Shift in Natural Gas Hydrates from First-Principles Solid-State NMR Calculations
}

Yuan Liu and Lars Ojamäe

\section{Linköping University Post Print}

\section{Tweet}

N.B.: When citing this work, cite the original article.

Original Publication:

Yuan Liu and Lars Ojamäe, C-13 Chemical Shift in Natural Gas Hydrates from First-Principles Solid-State NMR Calculations, 2016, The Journal of Physical Chemistry C, (120), 2, 11301136.

http://dx.doi.org/10.1021/acs.jpcc.5b11372

Copyright: American Chemical Society

http://pubs.acs.org/

Postprint available at: Linköping University Electronic Press

http://urn.kb.se/resolve?urn=urn:nbn:se:liu:diva-125313 


\title{
The ${ }^{13} \mathrm{C}$ Chemical Shift in Natural Gas Hydrates from First-Principles Solid-State NMR Calculations
}

\author{
Yuan Liu and Lars Ojamäe ${ }^{\dagger}$ \\ Department of Chemistry, IFM, Linköping University, SE-58 183 Linköping, Sweden \\ † Corresponding author. Phone: +46 13281380 Email address: lars@ifm.liu.se
}

\begin{abstract}
:
Natural gas hydrates (NGHs) are of interest both as a prospective energy resource and for possible technological applications. ${ }^{13} \mathrm{C}$ NMR technology is a powerful tool to characterize NGHs, and in this work the trends and origins of ${ }^{13} \mathrm{C}$ NMR chemical shifts of hydrocarbon molecules in NGHs from quantum-chemical first-principles calculations on solid state phases are presented. The chemical shift is found to decrease as the size of the water cavities increases for single occupancy NGHs, and to increase as the amount of $\mathrm{CH}_{4}$ increases for the multi-occupancy cases. In most cases, the chemical shift of NGHs monotonically increases as the external pressure increases. Furthermore, the chemical shift can be mainly attributed to the host-guest interaction together with a small contributions from water molecules for tight environments, and mainly depends on host-guest interaction for loose environments. The theoretical results provide useful information for identification of the types of clathrate phases and guest molecules included in NGH samples taken from natural sites.
\end{abstract}

Keywords: first-principles calculations; natural gas hydrate; solid-state NMR parameters; quantum-chemical computations; clathrates 


\section{INTRODUCTION}

Natural gas hydrates (NGHs) can be said to be a promising backup energy source since the amount of carbon included in NGHs on earth has been estimated to be at least twice the amount of that in all fossil fuels combined. ${ }^{1-4}$ Meanwhile, many technologies based on gas hydrates are being applied or developed, such as hydrogen storage, ${ }^{5-6} \mathrm{CO}_{2}$ sequestration, ${ }^{7-8}$ gas mixture separation, ${ }^{9-10}$ sea water desalination, ${ }^{11}$ and fire extinguishers using $\mathrm{CO}_{2}$ hydrate, ${ }^{12}$ etc. ${ }^{1}$ All the applications can be ascribed to the unique clathrate structures formed by frameworks of $\mathrm{H}$-bonded water molecules enclosing water cavities that are occupied by hydrocarbon or other gas molecules.

Different crystalline phases (e.g. sI, sII, sH, and sK etc.) of clathrate hydrates can be formed with various hydrocarbon molecules under appropriate temperature and pressure conditions. $^{1-2}$ These phases contain different kinds of H-bonded polyhedral water cavities: two dodecahedral (D or $5^{12}$, which designates that the cage wall can be visualized as constructed from 12 shared 5-membered rings of water molecules) and six tetrakaidecahedral ( $\mathbf{T}$ or $5^{12} 6^{2}$ ) cavities in a unit cell of phase I; sixteen D and eight hexakaidecahedral $(\mathbf{H}$ or $5^{12} 6^{4}$ ) cavities in a conventional unit cell of phase II; three D, two irregular dodecahedral (ID or $4^{3} 5^{6} 6^{3}$ ), and one icosahedral (I or $5^{12} 6^{8}$ ) cavity in a unit cell of phase $\mathrm{H}$; and three $\mathrm{D}$, two T, and two pentakaidecahedral ( $\mathbf{P}$ or $5^{12} 6^{3}$ ) cavities in a unit cell of phase K. ${ }^{1}$ A certain molecular species can be encapsulated into one or more cavities with varying occupancies in different crystalline phases. Especially, the NGH samples taken from the natural sites are usually very complex, and can include various hydrocarbon molecules and several clathrate phases. ${ }^{13}$ Since the NMR parameters are sensitive to the environment that a molecule experiences, ${ }^{13} \mathrm{C}$ NMR spectroscopy can be used to both qualitatively and quantitatively characterize NGHs.

Therefore, NMR measurements have been used experimentally to identify the types of crystalline phases, ${ }^{14-16}$ the kinds of hydrocarbon molecules, ${ }^{14,}{ }^{17-18}$ cage occupancies, ${ }^{17,}$ 19-20 hydration number, ${ }^{19}$ and to monitor dissociation processes and structural transformations, ${ }^{15-16 \text {, }}$ ${ }^{21-22}$ and to study guest dynamics. ${ }^{23}$ The ${ }^{13} \mathrm{C}$ chemical shifts of $\mathrm{CH}_{4}, \mathrm{C}_{2} \mathrm{H}_{6}$, and $\mathrm{C}_{3} \mathrm{H}_{8}$ in the sI and sII phases were presented in ref. $14 .{ }^{14}$ Kida et al. measured the ${ }^{13} \mathrm{C}$ NMR spectra of various hydrocarbon clathrate hydrates and explored trends of the chemical shift with temperature for various guest n-alkane. ${ }^{18}$ Gupta et al. investigated the dissociation process of methane hydrate through ${ }^{13} \mathrm{C}$ magic-angle spinning NMR measurements. ${ }^{22}$ The semiclathrate hydrates can be transformed to sII clathrates in the presence of methane as a coguest, which was elucidated with the help of NMR spectroscopy. ${ }^{15}$ However, only a limited number of 
quantum-chemical studies on NMR parameters in NGHs have been carried out until now. Ida et al. calculated the ${ }^{13} \mathrm{C}$ chemical shielding constants of methane enclosed in the small and large cage of sI hydrate using coupled perturbed Hatree-Fock method, and the electronic environments experienced by methane were also studied. ${ }^{24}$ The shielding constants and spinspin coupling constants of $\mathrm{CH}_{4}, \mathrm{C}_{2} \mathrm{H}_{6}$, and $\mathrm{C}_{3} \mathrm{H}_{8}$ encapsulated in the $5^{12}, 5^{12} 6^{2}$, and $5^{12} 6^{4}$ water cages were calculated at the level of B3LYP/HuzIII-su3 by Siuda and Sadlej. ${ }^{25-26}$ The chemical shifts of methane trapped in water clusters $\left(\mathrm{H}_{2} \mathrm{O}\right)_{19-25}$ were studied using B3LYP by Terleczky and Nyulászi. ${ }^{27}$

Several limitations are present in the theoretical studies on NMR parameters of hydrocarbon molecules in clathrate hydrates. For example, usually only isolated cluster models are employed in the simulations. ${ }^{24-27}$ The influences of the molecules beyond those of the cage wall are thus neglected. In addition, the dispersion interaction between guest hydrocarbon molecules and host water lattice is one of the most fundamental interactions in NGHs, which cannot be appropriately described by B3LYP. ${ }^{28-29}$ The experimental studies mainly focus on the guest molecules $\mathrm{CH}_{4}, \mathrm{C}_{2} \mathrm{H}_{6}$, and $\mathrm{C}_{3} \mathrm{H}_{8}$ in the sI and sII phases. To aid in the identification of the structures and compositions of complex NGH samples taken from natural sites, the NMR parameter data on more varieties of hydrocarbon molecules and clathrate phases are needed. In this work, the chemical shielding constants of $\mathrm{CH}_{4}, \mathrm{C}_{2} \mathrm{H}_{6}$, $\mathrm{C}_{3} \mathrm{H}_{8}, \mathrm{i}-\mathrm{C}_{4} \mathrm{H}_{10}$, and $\mathrm{n}-\mathrm{C}_{4} \mathrm{H}_{10}$ in sI, sII, sH, and sK clathrates are computed by the quantumchemical density functional theory (DFT) method augmented with dispersion corrections for periodic systems. The trends and origins of the ${ }^{13} \mathrm{C}$ chemical shift of hydrocarbon molecules in various clathrate hydrates are demonstrated.

\section{THEORETICAL METHODS}

The unit cell structures of sI, ${ }^{30} \mathrm{sII},{ }^{31} \mathrm{sH}^{32}$ and $\mathrm{sK}^{33}$ clathrates with single occupancy of each cavity by $\mathrm{CH}_{4}, \mathrm{C}_{2} \mathrm{H}_{6}, \mathrm{C}_{3} \mathrm{H}_{8}, \mathrm{i}-\mathrm{C}_{4} \mathrm{H}_{10}$, or $\mathrm{n}_{-} \mathrm{C}_{4} \mathrm{H}_{10}$ are depicted in Figure 1 . The initial lattice parameters and oxygen coordinates were taken from refs. 30-33. The hydrogen atoms were then randomly added and reoriented through 1 ns NVE dynamics simulation using the $\mathrm{CVFF}^{34}$ force field with oxygen atoms frozen which led to the fulfillment of the BernalFowler ${ }^{35}$ rules. The hydrocarbon molecules were initially placed in the center of each water cavity in various clathrates, while methane molecules were randomly put into the large cages of sH with reasonable intermolecular distances for multi-occupation structures. 


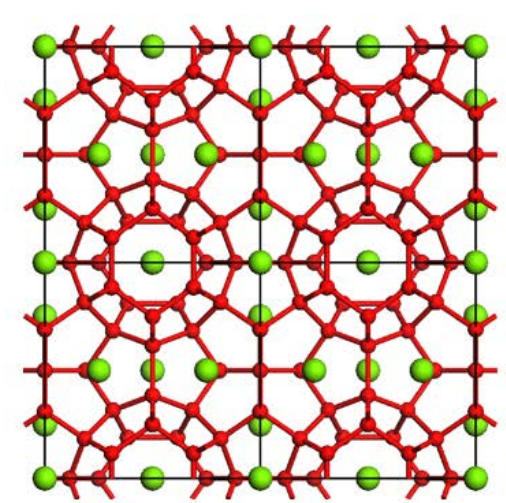

(a) $\mathrm{sI}$

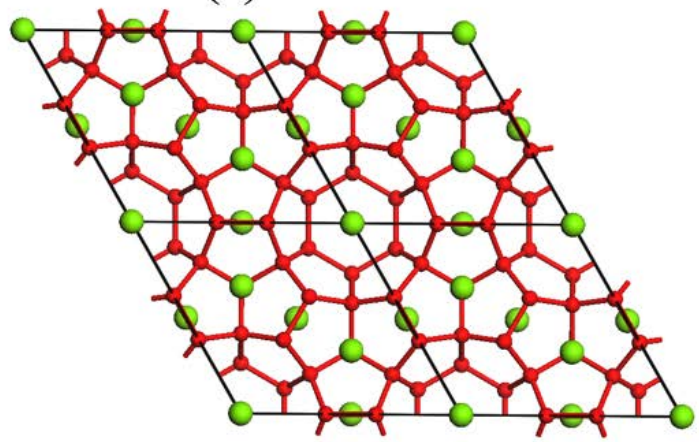

(c) $\mathrm{sH}$

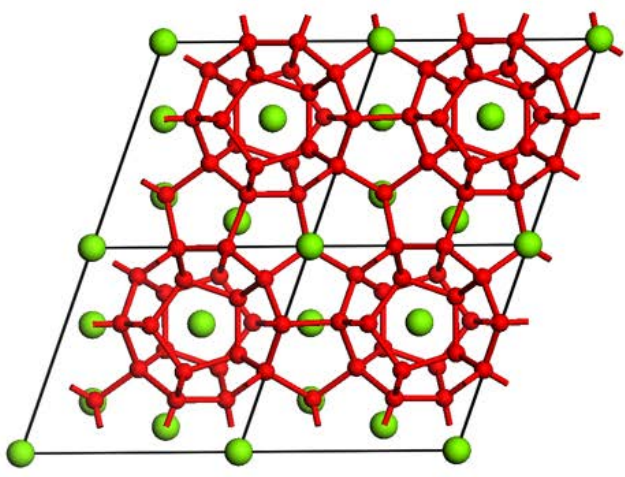

(b) SII

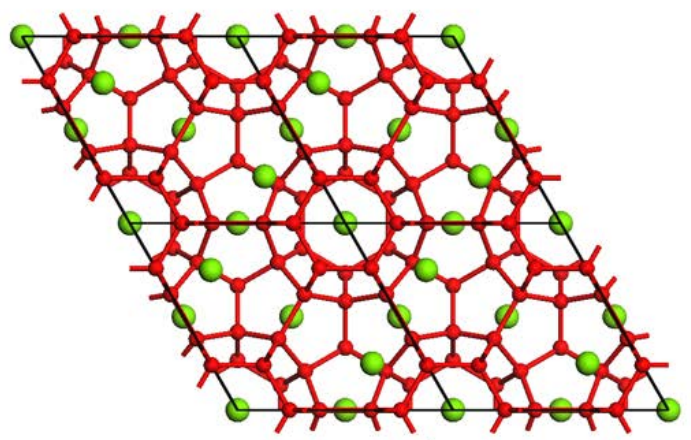

(d) $\mathrm{sK}$

Figure 1. The unit cell structures of clathrate hydrates: (a) phase I $\left(2 \mathrm{D} 6 \mathrm{~T} \cdot 46 \mathrm{H}_{2} \mathrm{O}\right)$, (b) primitive cell of phase II $\left(4 \mathrm{D} 2 \mathrm{H} \cdot 34 \mathrm{H}_{2} \mathrm{O}\right)$, (c) phase $\mathrm{H}\left(3 \mathrm{D} 2 \mathrm{ID} 1 \mathrm{I} \cdot 34 \mathrm{H}_{2} \mathrm{O}\right)$, (d) phase $\mathrm{K}$ $\left(3 \mathrm{D} 2 \mathrm{~T} 2 \mathrm{P} \bullet 40 \mathrm{H}_{2} \mathrm{O}\right)$. D, ID, T, P, H, and I represent the various water cavities $\left(5^{12}, 4^{3} 5^{6} 6^{3}, 5^{12} 6^{2}\right.$, $5^{12} 6^{3}, 5^{12} 6^{4}$, and $5^{12} 6^{8}$ ) in the different clathrate phases. The water molecules are represented by red balls, the hydrogen bonds are represented by red sticks, and the hydrocarbon molecules encapsulated in the various water cavities are represented by larger green balls.

To enable the guest molecules to obtain the proper orientations in the cavities, the initial crystal structures were first optimized using CVFF with the water molecules frozen. Then the structures were optimized by DFT calculations. In one set of calculations only the atom coordinates were optimized, and in another set both cell parameters and atom coordinates were fully relaxed. After the geometry optimizations, the NMR parameters were calculated from periodic first-principles calculations. Since the hydrogen bonds between water molecules and van der Waals (vdW) interactions between guest molecules and host lattice are the fundamental interactions in NGHs, the dispersion corrected DFT method PBE-TS ${ }^{36-37}$ are employed in all the calculations using the CASTEP ${ }^{38}$ module in Materials Studio 6.1. The energy cutoff used was $650 \mathrm{eV}$, and k-point net was set to $2 \times 2 \times 2$. The pseudopotentials were generated on the fly, which was a requirement of the NMR property calculation. The solidstate NMR chemical shielding constants of the carbon atoms in the NGHs are calculated by the first-principles linear response GIPAW (gauge-including projector augmented-wave) 
method. ${ }^{39-41}$ To explore the origin of ${ }^{13} \mathrm{C}$ chemical shift of hydrocarbon molecules in clathrate hydrates, the chemical shielding constants of the carbon atoms were split into contributions from different natural localized molecular orbitals (NLMO) ${ }^{42}$ based on a natural bond orbital (NBO) analysis. ${ }^{43-44}$ The NBO calculations were carried out with isolated cluster models (using the structures from refs. $45-46^{45-46}$ ) optimized by the $\omega \mathrm{B} 97 \mathrm{X}-\mathrm{D}^{47} / 6-311++\mathrm{G}(2 \mathrm{~d}, 2 \mathrm{p})^{48}$ method in the Gaussian 09 program. ${ }^{49}$

\section{RESULTS AND DISCUSSION}

3.1 Trends of ${ }^{13} \mathrm{C}$ Chemical Shift in NGHs. The ${ }^{13} \mathrm{C}$ chemical shielding constants $(\sigma)$ of $\mathrm{CH}_{4}, \mathrm{C}_{2} \mathrm{H}_{6}, \mathrm{C}_{3} \mathrm{H}_{8}, \mathrm{i}-\mathrm{C}_{4} \mathrm{H}_{10}$, and $\mathrm{n}-\mathrm{C}_{4} \mathrm{H}_{10}$ in sI, sII, sH, and sK clathrates were computed. The chemical shifts $(\delta)$ of the alkane molecules in NGHs were calculated relative the chemical shielding constant of methane in the gas phase as the reference: $\delta_{i}=\sigma_{\text {ref }}-\sigma_{i}$ (the subscript $i$ and ref represent each alkane molecule and the reference), ${ }^{40}$ as listed in Table 1 and Table 2.

Table 1. ${ }^{13} \mathrm{C}$ NMR chemical shift of $\mathrm{CH}_{4}$ in different cavities and phases of clathrate hydrates for fully optimized cell/cell lattice parameters fixed at the experimental values.

\begin{tabular}{|c|c|c|c|c|c|c|c|}
\hline \multicolumn{4}{|c|}{$\begin{array}{l}{ }^{13} \mathrm{C} \text { NMR Chemical Shift of } \mathrm{CH}_{4} \text { in Clathrate } \\
\text { Hydrate Relative to } \mathrm{CH}_{4} \text { in } \mathrm{Gas} \text { Phase /ppm }\end{array}$} & \multicolumn{4}{|c|}{$\begin{array}{c}\text { Chemical Shift Difference }(\Delta) \text { of } \mathrm{CH}_{4} \text { Enclosed } \\
\text { in Different Cavities /ppm }\end{array}$} \\
\hline $\mathrm{MH}$ & Small & Medium & Large & \multicolumn{3}{|c|}{ Theor. } & Expt. \\
\hline sI & $\mathbf{D}$ & - & $\mathbf{T}$ & \multicolumn{3}{|c|}{$\Delta_{\text {D-T }}$} & $\Delta_{\text {D-T }}$ \\
\hline 8CH $4 @$ @sI & $8.91 / 6.92$ & - & $6.12 / 4.39$ & \multicolumn{3}{|c|}{$2.79 / 2.53$} & $2.1^{a}\left(2.3^{b}\right)$ \\
\hline sK & D & $\mathbf{T}$ & $\mathbf{P}$ & $\Delta_{\text {D-T }}$ & $\Delta_{\text {D-P }}$ & $\Delta_{\text {T-P }}$ & - \\
\hline $7 \mathrm{CH}_{4} @ \mathrm{sK}$ & $9.21 / 7.22$ & $5.69 / 4.13$ & $4.90 / 3.57$ & $3.52 / 3.09$ & $4.31 / 3.65$ & $0.79 / 0.56$ & - \\
\hline sII & D & - & $\mathbf{H}$ & \multicolumn{3}{|c|}{$\Delta$ D-H } & $\Delta$ D-H \\
\hline 6CH 4 @sII & $8.62 / 6.91$ & - & $4.72 / 3.78$ & \multicolumn{3}{|c|}{$3.90 / 3.13$} & $3.75^{a}\left(3.54^{c}\right)$ \\
\hline sH & D & ID & I & $\Delta_{\text {D-ID }}$ & $\Delta$ D-I & $\Delta$ ID-I & - \\
\hline 6CH${ }_{4} @ \mathrm{sH}$ & $8.42 / 7.14$ & 7.99/6.66 & $4.62 / 3.68$ & $0.43 / 0.48$ & $3.80 / 3.46$ & $3.37 / 2.98$ & - \\
\hline 7CH $\mathrm{CH}_{4} @ \mathrm{sH}$ & $8.54 / 7.17$ & 7.98/6.63 & $4.91 / 3.95$ & \multicolumn{3}{|c|}{ - } & - \\
\hline $8 \mathrm{CH}_{4} @ \mathrm{sH}$ & $8.39 / 7.24$ & $7.97 / 6.70$ & $15.26 / 12.97$ & \multicolumn{3}{|c|}{-} & - \\
\hline 9CH${ }_{4} @ s H$ & $8.26 / 7.31$ & 7.76/6.66 & $16.83 / 14.16$ & \multicolumn{3}{|c|}{-} & - \\
\hline 10CH $\mathrm{CH}_{4} @ \mathrm{sH}$ & $8.06 / 7.32$ & 7.47/6.68 & 18.10/15.72 & \multicolumn{3}{|c|}{-} & - \\
\hline
\end{tabular}

${ }^{a}$ Reference 14. ${ }^{b}$ Reference 21. ${ }^{c}$ Reference 19.

The difference in chemical shift of methane between when in a small and when in a large cage of the sI clathrate is $2.79 \mathrm{ppm}$ for the fully optimized cell and $2.53 \mathrm{ppm}$ when the cell lattice was fixed at the experimental values, while the experimental value is 2.1 or $2.3 \mathrm{ppm} .{ }^{14,21}$ For the sII methane hydrate, the difference in methane chemical shift between small and large cages is $3.90 \mathrm{ppm}$ and $3.13 \mathrm{ppm}$ for the fully optimized cell and the cell lattice fixed, respectively, to be compared to 3.75 or 3.54 ppm experimentally. ${ }^{14,}{ }^{19}$ In addition, the ${ }^{13} \mathrm{C}$ NMR peaks of propane in sII hydrate are located at 31.35 ppm for methylene-C and at 32.59 
ppm for methyl-C relative methane in the gas phase in our simulation (see Table 2), which can be compared to $16.79 \mathrm{ppm}$ for methylene carbon and $17.57 \mathrm{ppm}$ for methyl carbon determined by adamantane as external reference. ${ }^{50}$ The shielding of propane's methylene- $\mathrm{C}$ is greater than that of its methyl-C by water cages in agreement with experiment, and the chemical shift difference between methylene- $\mathrm{C}$ and methyl- $\mathrm{C}$ of $\mathrm{C}_{3} \mathrm{H}_{8}$ is $1.24 \mathrm{ppm}$ from computation vs. $0.78 \mathrm{ppm}$ from experiment (note that the experiment uses a solid as a reference, whereas it for us is more convenient with a gaseous reference state, but since we are looking at differences between shifts the reference state does not matter). Thus, the computational results in this work are consistent with the experimental reports, and differ less than 1 ppm in comparison with measurements for sI and sII methane hydrates.

Table 2. ${ }^{13} \mathrm{C}$ NMR chemical shift of the larger hydrocarbon molecules $\left(\mathrm{C}_{2} \mathrm{H}_{6}, \mathrm{C}_{3} \mathrm{H}_{8}, \mathrm{i}-\mathrm{C}_{4} \mathrm{H}_{10}\right.$ and $n-\mathrm{C}_{4} \mathrm{H}_{10}$ ) encapsulated in the large cavities of different clathrate hydrates, where simultaneously the small cavities are occupied by methane.

\begin{tabular}{|c|c|c|c|c|c|c|c|c|c|c|c|c|}
\hline \multicolumn{13}{|c|}{${ }^{3} \mathrm{C}$ NMR Chemical Shift of Guest Molecules in Clathrate Hydrate Relative to $\mathrm{CH}_{4}$ in Gas Phase /ppm } \\
\hline \multirow{2}{*}{\multicolumn{2}{|c|}{ Guest molecules }} & \multicolumn{2}{|c|}{ sI } & \multicolumn{3}{|c|}{ sK } & \multicolumn{2}{|c|}{ sII } & \multicolumn{3}{|c|}{ sH } & \multirow{2}{*}{$\begin{array}{c}\text { Gas } \\
\text { phase }\end{array}$} \\
\hline & & D & $\mathbf{T}$ & D & $\mathbf{T}$ & $\mathbf{P}$ & D & H & D & ID & I & \\
\hline \multicolumn{2}{|c|}{$\mathrm{CH}_{4}$} & 8.56 & - & 9.16 & 5.69 & - & 8.69 & - & 8.38 & 7.96 & - & - \\
\hline \multicolumn{2}{|c|}{$\mathrm{C}_{2} \mathrm{H}_{6}$} & - & 22.31 & - & - & 20.64 & - & 20.30 & - & - & 20.14 & 17.39 \\
\hline \multicolumn{2}{|c|}{$\mathrm{CH}_{4}$} & - & - & 9.12 & 5.38 & - & 8.59 & - & 8.46 & 7.97 & - & - \\
\hline \multirow{2}{*}{$\mathrm{C}_{3} \mathrm{H}_{8}$} & $\mathrm{CH}_{2-}^{-}$ & - & - & - & - & 30.62 & - & 31.35 & - & - & 31.41 & 31.10 \\
\hline & $-\mathrm{CH}_{3}$ & - & - & - & - & 33.91 & - & 32.59 & - & - & 30.55 & 27.53 \\
\hline \multicolumn{2}{|c|}{$\mathrm{CH}_{4}$} & - & - & 8.73 & 5.20 & - & 8.33 & - & 8.47 & 8.02 & - & - \\
\hline \multirow{2}{*}{$\mathrm{i}-\mathrm{C}_{4} \mathrm{H}_{10}$} & -CH- & - & - & - & - & 37.68 & - & 38.33 & - & - & 39.98 & 39.45 \\
\hline & $-\mathrm{CH}_{3}$ & - & - & - & - & 43.32 & - & 41.88 & - & - & 38.49 & 35.66 \\
\hline \multicolumn{2}{|c|}{$\mathrm{CH}_{4}$} & - & - & 8.57 & 5.36 & - & 8.36 & - & 8.54 & 7.98 & - & - \\
\hline \multirow{2}{*}{$\begin{array}{l}\text { n- } \\
\mathrm{C}_{4} \mathrm{H}_{10}\end{array}$} & $-\overline{\mathrm{CH}_{2-}}$ & - & - & - & - & 38.95 & - & 37.50 & - & - & 41.61 & 41.29 \\
\hline & $-\mathrm{CH}_{3}$ & - & - & - & - & 31.10 & - & 27.88 & - & - & 28.41 & 25.89 \\
\hline
\end{tabular}

The ${ }^{13} \mathrm{C}$ chemical shift of methane in various NGHs are depicted in Figure 2. For single occupancy of each water cavity in NGHs, the trend is that the chemical shift of methane decreases as the size of water cavity increases (see Figure 2a). This is consistent with the experimental observations: the chemical shifts of methane in the $\mathrm{D}, \mathrm{T}$, and $\mathrm{H}$ cages are -4.0 (in sI) or -3.95 (in sII) ppm, -6.1 ppm, and -7.7 ppm relative to tetramethylsilane, ${ }^{14}-4.14$ (in sI) or -4.04 (in sII) ppm, $-6.52 \mathrm{ppm}$, and $-7.88 \mathrm{ppm}$ relative to adamantane, ${ }^{17}$ respectively. If the water cavities are occupied by more than one methane molecule, the chemical shift of methane increases as the amount of methane increases (see Figure 2b). The two phenomenon are related since increasing the amount of methane in a cage is equivalent to decreasing the average space per methane molecule. The chemical shift of methane in the fully optimized 
cell is larger than that in the cell with the experimental cell parameters, since the radius of the water cavities become smaller after full optimization of the cell lattice.

(a)
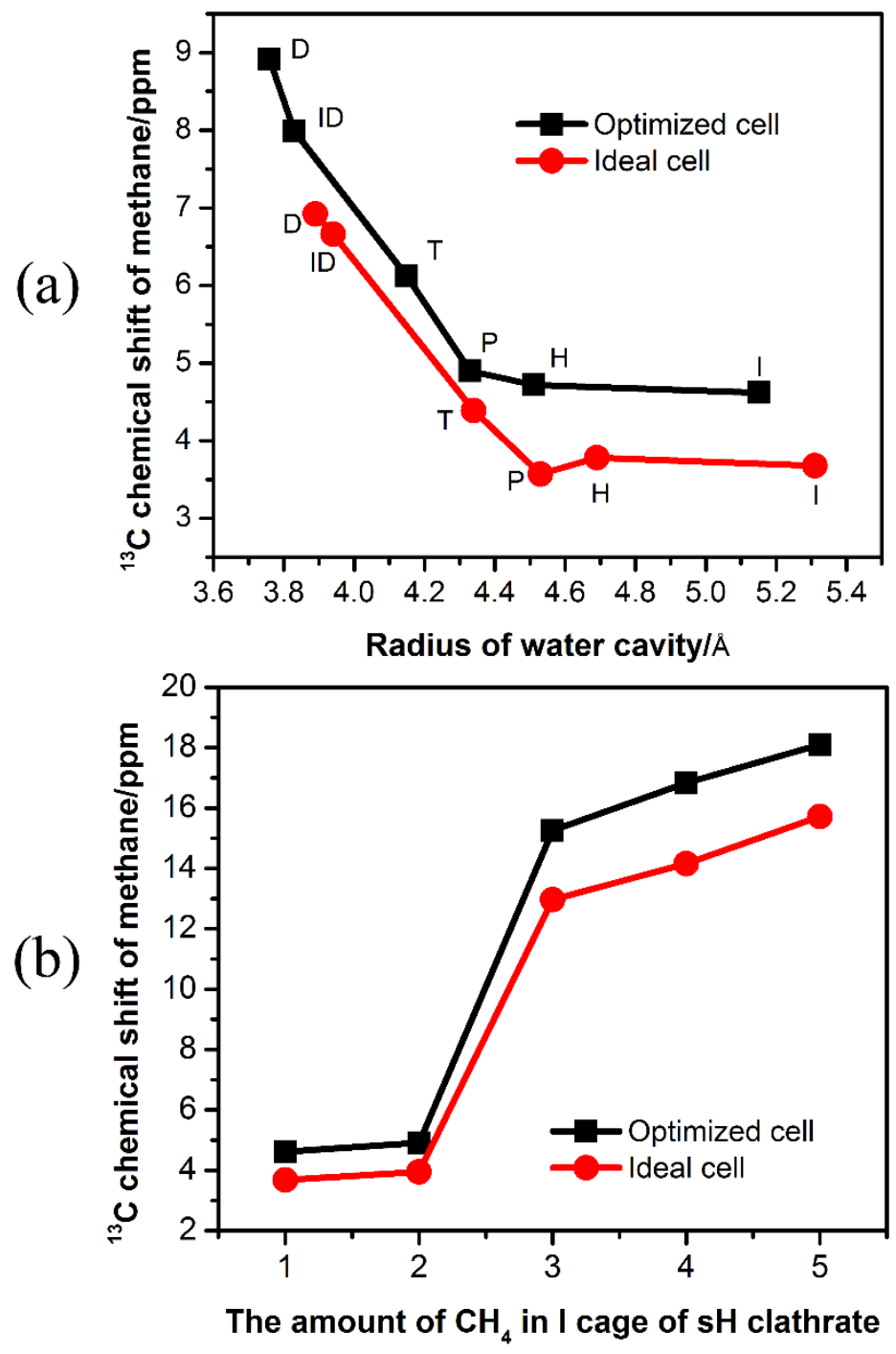

Figure 2. The ${ }^{13} \mathrm{C}$ NMR chemical shift of methane in different phases of clathrate hydrates: (a) the chemical shift as a function of cavity size of methane enclosed in different types of water cavities of clathrate hydrates, (b) the chemical shift as a function of number of methane molecules occupying the large water cavity of the phase $\mathrm{H}$ clathrate hydrate. Note: optimized cell means that both the atom coordinates and cell lattice parameters were optimized; ideal cell means the cell lattice parameters were fixed at the experimental values, and only the atom coordinates were optimized.

The ${ }^{13} \mathrm{C}$ chemical shift of $\mathrm{C}_{2} \mathrm{H}_{6}, \mathrm{C}_{3} \mathrm{H}_{8}, \mathrm{i}-\mathrm{C}_{4} \mathrm{H}_{10}$, and $n-\mathrm{C}_{4} \mathrm{H}_{10}$ in sI, sII, sH, and sK clathrates are presented in Figure 3. For $\mathrm{C}_{2} \mathrm{H}_{6}, \mathrm{C}_{3} \mathrm{H}_{8}$, and $\mathrm{i}-\mathrm{C}_{4} \mathrm{H}_{10}$, the chemical shifts all decrease as the sizes of the water cavities increase. The experimental chemical shift of ethane 
enclosed in T cages of sI and $\mathrm{H}$ cages of sII are respectively $7.7 \mathrm{ppm}$ and $6.4 \mathrm{ppm}$ relative to tetramethylsilane. ${ }^{14}$ A similar result that the chemical shift is $7.95 \mathrm{ppm}$ and $6.50 \mathrm{ppm}$ for ethane in the $\mathrm{T}$ and $\mathrm{H}$ cavities relative to adamantane was also reported by Kida et al. ${ }^{17}$ The experimental measurements also show that the chemical shift of $\mathrm{C}_{2} \mathrm{H}_{6}$ decrease as the size of water cavity increase. From the computations we see that the chemical shift decrease and then increase as the sizes of water cavities increase for $n-\mathrm{C}_{4} \mathrm{H}_{10}$ in sK, sII, and sH phases. This behavior is due to different isomers (trans $n-\mathrm{C}_{4} \mathrm{H}_{10}$ and gauche $n-\mathrm{C}_{4} \mathrm{H}_{10}$ ) being encapsulated in the sK, sII, and sH phases. Gauche $n-\mathrm{C}_{4} \mathrm{H}_{10}$ is present in the sK clathrate where it has a dihedral angle of $60.3^{\circ}$ and in the sII clathrate with the dihedral angle $58.3^{\circ}$, but the large cages of the $\mathrm{sH}$ clathrate are occupied by trans $\mathrm{n}-\mathrm{C}_{4} \mathrm{H}_{10}$ with the dihedral angle $179.9^{\circ}$.

Kida et al. reported that the ${ }^{13} \mathrm{C}$ chemical shifts of the methyl and methylene carbons of $\mathrm{C}_{3} \mathrm{H}_{8}$ are reversed in sII clathrate as compared to in the gas phase. ${ }^{50}$ The same phenomenon is seen in our calculations shown in Table 2: the chemical shift of methyl-C is greater than that of methylene-C when propane enclosed in the P cavities of sK clathrate and in the $\mathrm{H}$ cavities of sII clathrate. However, for the larger I cage in the sH hydrate the shifts goes in the same direction as in the gas phase, which might indicate that $\mathrm{C}_{3} \mathrm{H}_{8}$ in the large cavity experiences a such a loose environment with weak host-guest interaction so that the shifts behave more like in the gas phase. The same phenomenon can be observed in Table 2 for $\mathrm{i}-\mathrm{C}_{4} \mathrm{H}_{10}$.

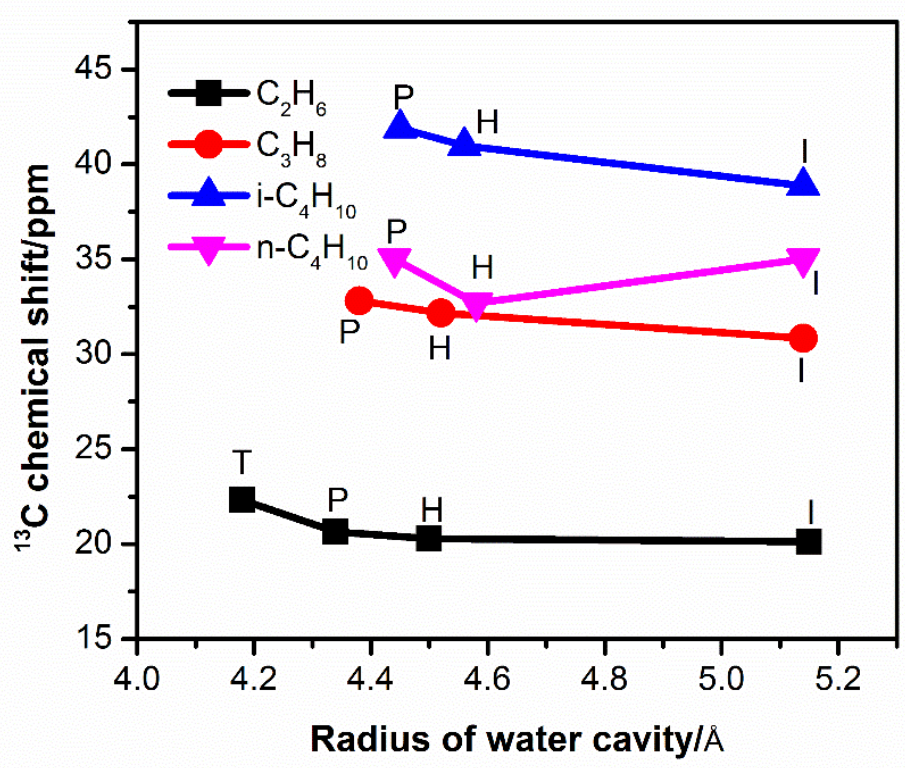

Figure 3. The ${ }^{13} \mathrm{C}$ NMR chemical shift of larger hydrocarbon molecules $\left(\mathrm{C}_{2} \mathrm{H}_{6}, \mathrm{C}_{3} \mathrm{H}_{8}\right.$, i$\mathrm{C}_{4} \mathrm{H}_{10}$ and $n-\mathrm{C}_{4} \mathrm{H}_{10}$ ) encapsulated in the large cavities of different clathrate hydrates as a function of cavity size, where simultaneously the small cavities are occupied by methane. 
3.2 Origin of ${ }^{13} \mathbf{C}$ Chemical Shift in NGHs. To elucidate the origin of the ${ }^{13} \mathrm{C}$ chemical shift in NGHs, the chemical shielding constants of methane in gas phase and in the water cavities of various clathrates are split into the contributions from each NLMO based on a NBO analysis (see Table 3). The contribution from the carbon core is seen to be almost the same irrespective of whether methane is in the gas phase or in water cavities of clathrates. The contributions from the water molecules (sum of the contributions from $\mathrm{OH}$ bonds, oxygen core, and lone pair electrons of oxygen atoms) of the water cavities are $2.27,0.89,0.10,0.30$, and $-0.42 \mathrm{ppm}$ for $\mathrm{CH}_{4}$ enclosed in the $\mathrm{D}, \mathrm{ID}, \mathrm{T}, \mathrm{P}$, and $\mathrm{H}$ cage, respectively. Thus, for methane in a D cage, the chemical shift can be mainly attributed to the electrons in $\mathrm{CH}$ bonding orbitals and only a small part is due to the water molecules. The ratios of guest diameter to cavity diameter (RGTC) are 0.855 (in sI) or 0.868 (in sII) for methane in the D cage, while 0.744 and 0.652 for methane in the $\mathrm{T}$ and in the $\mathrm{H}_{\text {cage. }}{ }^{2}$ When $\mathrm{CH}_{4}$ is in a loose environment (the RGTC is relatively small), the chemical shift almost completely can be attributed to the contributions from $\mathrm{CH}$ bond electrons. Since the electronic distribution of the $\mathrm{CH}$ bond is influenced by the van der Waals interaction between the guest alkane molecule and the host water cage wall, we can conclude that the chemical shift of methane depends on the host-guest interaction with a small contribution from the water molecules when $\mathrm{CH}_{4}$ is in a relatively tight environment, and mainly determined by the host-guest interaction when $\mathrm{CH}_{4}$ experiences a relatively loose environment.

Table 3. ${ }^{13} \mathrm{C}$ NMR chemical shielding constants of methane in the gas phase and encapsulated in the water cavities in various clathrate hydrates split into the contributions from each natural localized molecular orbitals (NLMO), and the paramagnetic and diamagnetic components of the chemical shielding constant. BD, CR, and LP represent bond, core, and lone electron pairs. Unit: ppm

\begin{tabular}{|c|c|c|c|c|c|c|c|c|c|}
\hline & \multicolumn{3}{|c|}{$\mathrm{CH}_{4}$ in gas phase } & \multicolumn{3}{|c|}{$\mathrm{CH}_{4} @ \mathbf{D}$ cage } & \multicolumn{3}{|c|}{$\mathrm{CH}_{4} @$ ID cage } \\
\hline NLMO & Total & $\sigma^{\text {para }}$ & $\sigma^{\text {dia }}$ & Total & $\sigma^{\text {para }}$ & $\sigma^{\text {dia }}$ & Total & $\sigma^{\text {para }}$ & $\sigma^{\text {dia }}$ \\
\hline $\mathrm{BD} \mathrm{OH}$ & - & - & - & 8.50 & -14.33 & 22.83 & 7.97 & -14.82 & 22.79 \\
\hline BD CH & -9.80 & -51.63 & 41.83 & $\begin{array}{l}-17.37 \\
\end{array}$ & -65.28 & 47.91 & -15.90 & -58.97 & 43.07 \\
\hline CR O & - & - & - & -1.29 & -1.19 & -0.10 & -1.21 & -1.12 & -0.09 \\
\hline CR C & 203.72 & 0.01 & 203.71 & 203.72 & 0.01 & 203.71 & 203.72 & 0.01 & 203.71 \\
\hline LP O & - & - & - & -4.94 & -3.45 & -1.49 & -5.87 & -4.04 & -1.83 \\
\hline sum & 193.92 & -51.62 & 245.54 & 188.62 & -84.24 & 272.86 & 188.71 & -78.94 & 267.65 \\
\hline & \multicolumn{3}{|c|}{$\mathrm{CH}_{4} @ \mathbf{T}$ cage } & \multicolumn{3}{|c|}{$\mathrm{CH}_{4} @ \mathbf{P}$ cage } & \multicolumn{3}{|c|}{$\mathrm{CH}_{4} @ \mathbf{H}$ cage } \\
\hline NLMO & Total & $\sigma^{\text {para }}$ & $\overline{\sigma^{\text {dia }}}$ & Total & $\sigma^{\text {para }}$ & $\overline{\sigma^{\text {dia }}}$ & Total & $\sigma^{\text {para }}$ & $\overline{\sigma^{\text {dia }}}$ \\
\hline BD OH & 8.60 & -16.00 & 24.60 & 8.99 & -16.53 & 25.52 & 9.03 & -17.27 & 26.30 \\
\hline BD CH & -14.64 & -56.56 & 41.92 & -13.76 & -54.66 & 40.90 & -11.95 & -49.73 & 37.78 \\
\hline CR O & -1.20 & -1.10 & -0.10 & -1.20 & -1.10 & -0.10 & -1.15 & -1.04 & -0.11 \\
\hline
\end{tabular}




\begin{tabular}{|c|c|c|c|c|c|c|c|c|c|}
\hline CR C & 203.72 & 0.01 & 203.71 & 203.72 & 0.01 & 203.71 & 203.72 & 0.01 & 203.71 \\
\hline LP O & -7.30 & -4.52 & -2.78 & -7.49 & -4.53 & -2.96 & -8.30 & -4.78 & -3.52 \\
\hline sum & 189.18 & -78.17 & 267.35 & 190.26 & -76.81 & 267.07 & 191.35 & -72.81 & 264.16 \\
\hline
\end{tabular}

In Table 4, the ${ }^{13} \mathrm{C}$ chemical shielding of $\mathrm{C}_{3} \mathrm{H}_{8}$ in the gas phase and in the sK and sII clathrate phases are also split into the contributions from each NLMO using the same method as with methane. The contribution from the carbon core is also almost equal for all cases. The contributions from the water molecules of the $\mathrm{P}$ and $\mathrm{H}$ cages are -1.35 and $-0.93 \mathrm{ppm}$ for methyl-C, and 2.42 and 1.14 ppm for methylene- $\mathrm{C}$ of $\mathrm{C}_{3} \mathrm{H}_{8}$, respectively. For propane in the sK and sII phases, the chemical shift mainly depends on the contributions from the electrons in the $\mathrm{CH}$ and $\mathrm{CC}$ bonding orbitals with a small contribution from water. Considering the RGTC (0.943) of $\mathrm{C}_{3} \mathrm{H}_{8}$ and large cavity of sII, ${ }^{2}$ this is to be expected since the environment is relatively tight. In addition, the chemical shielding effect of methyl-C and methylene-C of $\mathrm{C}_{3} \mathrm{H}_{8}$ in the gas phase and in clathrate phase is different. In the gas phase, the shielding around methyl-C is greater than that around methylene-C, but the shielding is slightly larger around methylene-C than methyl-C in the sK and sII phases, which is consistent with the NMR measurements from Kida et al. where they found that the chemical shifts of methyl and methylene carbons of propane encaged in sII clathrates were reversed compared to in gaseous propane. $^{50}$

Table 4. ${ }^{13} \mathrm{C}$ NMR chemical shielding constants of $\mathrm{C}_{3} \mathrm{H}_{8}$ in the gas phase and encapsulated in the water cavities in various clathrate hydrates split into the contributions from each natural localized molecular orbitals (NLMO), and the paramagnetic and diamagnetic components of the chemical shielding constant. BD, CR, and LP represents bond, core, and lone electron pairs. Unit: ppm

\begin{tabular}{|c|c|c|c|c|c|c|c|c|c|}
\hline$-\mathrm{CH}_{3}$ & \multicolumn{3}{|c|}{$\mathrm{C}_{3} \mathrm{H}_{8}$ in gas phase } & \multicolumn{3}{c|}{$\mathrm{C}_{3} \mathrm{H}_{8} @ \mathbf{P}$ cage } & \multicolumn{3}{c|}{$\mathrm{C}_{3} \mathrm{H}_{8} @ \mathbf{H}$ cage } \\
\hline $\mathrm{NLMO}$ & Total & $\sigma^{\text {para }}$ & $\sigma^{\text {dia }}$ & Total & $\sigma^{\text {para }}$ & $\sigma^{\text {dia }}$ & Total & $\sigma^{\text {para }}$ & $\sigma^{\text {dia }}$ \\
\hline BD OH & - & - & - & 7.86 & -18.02 & 25.88 & 8.36 & -18.22 & 26.58 \\
\hline BD CH & -15.13 & -45.69 & 30.56 & 2.46 & -25.08 & 27.54 & 9.33 & -20.33 & 29.66 \\
\hline BD CC & -17.15 & -26.62 & 9.47 & -38.06 & -41.49 & 3.43 & -43.61 & -45.78 & 2.17 \\
\hline CR O & - & - & - & -1.66 & -1.54 & -0.12 & -1.47 & -1.36 & -0.11 \\
\hline CR C & 203.51 & -0.12 & 203.63 & 203.32 & -0.30 & 203.62 & 203.30 & -0.31 & 203.61 \\
\hline LP O & - & - & - & -7.55 & -6.37 & -1.18 & -7.82 & -5.69 & -2.13 \\
\hline sum & 171.23 & -72.43 & 243.66 & 166.37 & -92.80 & 259.17 & 168.09 & -91.69 & 259.78 \\
\hline$-\mathrm{CH}_{2}-$ & \multicolumn{2}{|c|}{$\mathrm{C}_{3} \mathrm{H}_{8}$ in gas phase } & \multicolumn{3}{|c|}{$\mathrm{C}_{3} \mathrm{H}_{8} @ \mathbf{P}$ cage } & \multicolumn{3}{c|}{$\mathrm{C}_{3} \mathrm{H}_{8} @ \mathbf{H}$ cage } \\
\hline $\mathrm{NLMO}^{2}$ Total & $\sigma^{\text {para }}$ & $\sigma^{\text {dia }}$ & \multicolumn{2}{|c|}{ Total } & $\sigma^{\text {para }}$ & $\sigma^{\text {dia }}$ & \multicolumn{2}{|c|}{ Total } & \multicolumn{2}{c|}{$\sigma^{\text {para }}$} & $\sigma^{\text {dia }}$ \\
\hline BD OH & - & - & - & 9.23 & -16.67 & 25.90 & 9.28 & -17.49 & 26.77 \\
\hline BD CH & -10.55 & -33.02 & 22.47 & -54.37 & -75.06 & 20.69 & -57.56 & -80.48 & 22.92 \\
\hline BD CC & -23.28 & -37.58 & 14.30 & 17.18 & -13.21 & 30.39 & 22.15 & -11.13 & 33.28 \\
\hline CR O & - & - & - & -1.62 & -1.51 & -0.11 & -1.45 & -1.34 & -0.11 \\
\hline CR C & 203.17 & -0.26 & 203.43 & 202.90 & -0.60 & 203.50 & 202.75 & -0.74 & 203.49 \\
\hline LP O & - & - & - & -5.19 & -4.14 & -1.05 & -6.69 & -4.26 & -2.43 \\
\hline
\end{tabular}




\begin{tabular}{|l|l|l|l|l|l|l|l|l|l|} 
sum & 169.34 & -70.86 & 240.20 & 168.12 & -111.20 & 279.32 & 168.48 & -115.44 & 283.92 \\
\hline
\end{tabular}

3.3 Dependence of the ${ }^{13} \mathrm{C}$ Chemical Shift in NGHs with External Pressure. The ${ }^{13} \mathrm{C}$ chemical shifts in NGHs as a function of the external pressure are presented in Figure 4. The ${ }^{13} \mathrm{C}$ chemical shifts in pure sI and sII methane hydrate and in sII $\mathrm{CH}_{4}-\mathrm{C}_{3} \mathrm{H}_{8}$ hydrate were computed in the pressure range $-300 \mathrm{MPa}$ to $800 \mathrm{MPa}$. The negative pressure corresponds to an expansion of the clathrate cell. As shown in the upper panel of Figure 4, the chemical shifts of methane in both the small and large cavities of sI phase monotonically increase as the pressure increase. Quite similar trends are seen for $\mathrm{CH}_{4}$ encapsulated in the small and large cavities of the sII phase, while the slope decreases for methane in the large cavities of sII at higher pressure compared to the trend for the small cavities (shown in the middle figure of Figure 4). For the $\mathrm{CH}_{4}-\mathrm{C}_{3} \mathrm{H}_{8}$ sII hydrate, the chemical shift of methane in the small cavities increase monotonically as the pressure increases. The chemical shift of propane in the large cavities of sII also gradually increase as the external pressure increases. However, the trends for methyl-C and methylene- $\mathrm{C}$ of $\mathrm{C}_{3} \mathrm{H}_{8}$ differ. The methylene- $\mathrm{C}$ is more shielded than that of methyl-C, which is consistent with the result the chemical shift of methyl-C and methylene-C of $\mathrm{C}_{3} \mathrm{H}_{8}$ in sII clathrate being $17.57 \mathrm{ppm}$ and $16.79 \mathrm{ppm}$ from experimental measurements, respectively. ${ }^{50}$ As the pressure increases, the chemical shift of methyl-C increases while that of methylene-C slightly decreases. 


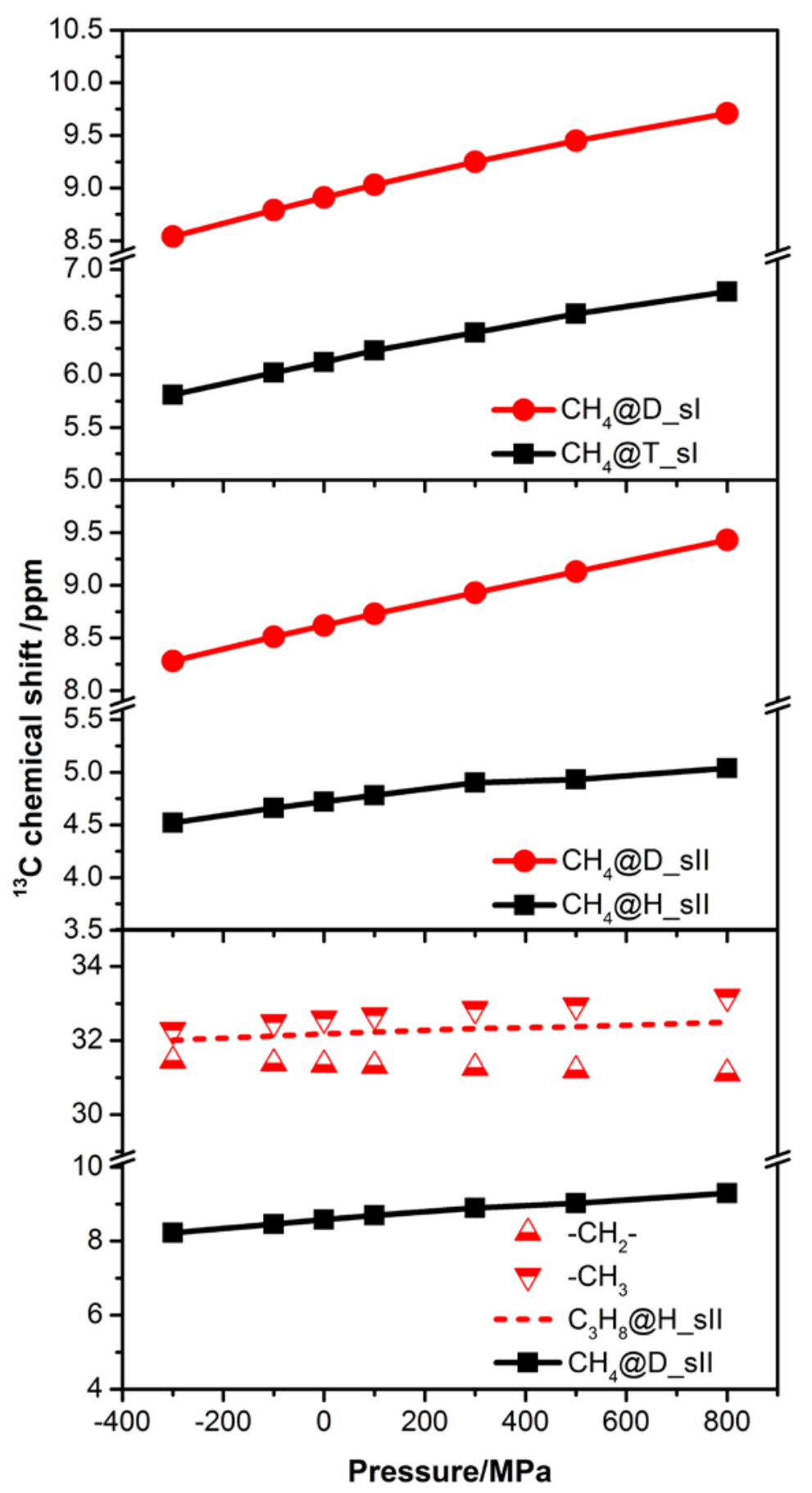

Figure 4. The ${ }^{13} \mathrm{C}$ NMR chemical shift of pure sI and sII methane hydrate and of $\mathrm{CH}_{4}-\mathrm{C}_{3} \mathrm{H}_{8}$ mixed sII hydrate as a function of external pressure.

\section{CONCLUSIONS}

The trends and origins of the ${ }^{13} \mathrm{C}$ NMR chemical shift of hydrocarbon molecules in NGHs from first-principles calculations on solid state phases were presented in this work. For single 
occupancy $\mathrm{CH}_{4}$ hydrates, the chemical shift decreases as the size of the water cavities increase. For multi-occupancy cases, the chemical shift increases as the amount of $\mathrm{CH}_{4}$ increase. For $\mathrm{C}_{2} \mathrm{H}_{6}, \mathrm{C}_{3} \mathrm{H}_{8}, \mathrm{i}-\mathrm{C}_{4} \mathrm{H}_{10}$, and $\mathrm{n}-\mathrm{C}_{4} \mathrm{H}_{10}$ hydrates, the chemical shift all gradually decrease as the size of the water cavities increase. Furthermore, the chemical shifts of pure sI and sII $\mathrm{CH}_{4}$ hydrate and of sII $\mathrm{CH}_{4}-\mathrm{C}_{3} \mathrm{H}_{8}$ hydrate increase as the external pressure increases. The chemical shift can be mainly attributed to the host-guest interaction with a small contributions from water molecules when the guest molecule is in a relatively tight environment, whereas it mainly depends on only the host-guest interaction when the guest molecule experiences a relatively loose environment. The theoretical results in this paper will enlarge the database of ${ }^{13} \mathrm{C}$ NMR parameters of NGHs and provide valuable information to help identify the types of clathrate phases and varieties of guest molecules included in NGH samples taken from natural sites.

\section{ACKNOWLEDGEMENTS}

This work is supported by the Swedish Research Council (VR), the Swedish Supercomputer Center (SNIC/NSC), and a scholarship under the State Scholarship Fund of China Scholarship Council (File No. 201206060016). 


\section{REFERENCES}

1. Sloan, E. D.; Koh, C. A., Clathrate Hydrates of Natural Gases. Third ed.; CRC Press/Taylor\&Francis Group: Boca Raton: 2008.

2. Sloan, E. D., Fundamental Principles and Applications of Natural Gas Hydrates. Nature 2003, 426, 353-359.

3. Koh, C. A., Towards a Fundamental Understanding of Natural Gas Hydrates. Chem. Soc. Rev. 2002, 31, 157167.

4. Koh, C. A.; Sum, A. K.; Sloan, E. D., Gas Hydrates: Unlocking the Energy from Icy Cages. J. Appl. Phys. 2009, 106, 061101.

5. Mao, W. L.; Mao, H. K.; Goncharov, A. F.; Struzhkin, V. V.; Guo, Q. Z.; Hu, J. Z.; Shu, J. F.; Hemley, R. J.; Somayazulu, M.; Zhao, Y. S., Hydrogen Clusters in Clathrate Hydrate. Science 2002, 297, 2247-2249.

6. Florusse, L. J.; Peters, C. J.; Schoonman, J.; Hester, K. C.; Koh, C. A.; Dec, S. F.; Marsh, K. N.; Sloan, E. D., Stable Low-Pressure Hydrogen Clusters Stored in a Binary Clathrate Hydrate. Science 2004, 306, 469-471.

7. Voronov, V. P.; Gorodetskii, E. E.; Muratov, A. R., Experimental Study of Methane Replacement in Gas Hydrate by Carbon Dioxide. J. Phys. Chem. B 2010, 114, 12314-12318.

8. Bai, D. S.; Zhang, X. R.; Chen, G. J.; Wang, W. C., Replacement Mechanism of Methane Hydrate with Carbon Dioxide from Microsecond Molecular Dynamics Simulations. Energy Environ. Sci. 2012, 5, 7033-7041.

9. Cha, I.; Lee, S.; Lee, J. D.; Lee, G. W.; Seo, Y., Separation of SF6 from Gas Mixtures Using Gas Hydrate Formation. Environ. Sci. Technol. 2010, 44, 6117-6122.

10. Seo, Y.; Tajima, H.; Yamasaki, A.; Takeya, S.; Ebinuma, T.; Kiyono, F., A New Method for Separating HFC134a from Gas Mixtures Using Clathrate Hydrate Formation. Environ. Sci. Technol. 2004, 38, 4635-4639.

11. Cha, J. H.; Seol, Y., Increasing Gas Hydrate Formation Temperature for Desalination of High Salinity Produced Water with Secondary Guests. ACS Sustain. Chem. Eng. 2013, 1, 1218-1224.

12. Hatakeyama, T.; Aida, E.; Yokomori, T.; Ohmura, R.; Ueda, T., Fire Extinction Using Carbon Dioxide Hydrate. Ind. Eng. Chem. Res. 2009, 48, 4083-4087.

13. Chazallon, B.; Focsa, C.; Charlou, J. L.; Bourry, C.; Donval, J. P., A Comparative Raman Spectroscopic Study of Natural Gas Hydrates Collected at Different Geological Sites. Chem. Geol. 2007, 244, 175-185.

14. Subramanian, S.; Kini, R. A.; Dec, S. F.; Sloan, E. D., Evidence of Structure II Hydrate Formation from Methane Plus Ethane Mixtures. Chem. Eng. Sci. 2000, 55, 1981-1999.

15. Lee, S.; Lee, Y.; Park, S.; Seo, Y., Structural Transformation of Isopropylamine Semiclathrate Hydrates in the Presence of Methane as a Coguest. J. Phys. Chem. B 2012, 116, 13476-13480.

16. Gao, S. Q.; Chapman, W. G.; House, W., Application of Low Field NMR $\mathrm{T}_{2}$ Measurements to Clathrate Hydrates. J. Magn. Reson. 2009, 197, 208-212.

17. Kida, M.; Sakagami, H.; Takahashi, N.; Hachikubo, A.; Shoji, H.; Kamata, Y.; Ebinuma, T.; Narita, H.; Takeya, S., Estimation of Gas Composition and Cage Occupancies in $\mathrm{CH}_{4}-\mathrm{C}_{2} \mathrm{H}_{6}$ Hydrates by CP-MAS ${ }^{13} \mathrm{C}$ NMR Technique. J. Jpn. Pet. Inst. 2007, 50, 132-138.

18. Kida, M.; Sakagami, H.; Takahashi, N.; Nagao, J., Chemical Shift Changes and Line Narrowing in ${ }^{13} \mathrm{C}$ NMR Spectra of Hydrocarbon Clathrate Hydrates. J. Phys. Chem. A 2013, 117, 4108-4114.

19. Ripmeester, J. A.; Ratcliffe, C. I., Low-Temperature Cross-Polarization Magic Angle Spinning ${ }^{13} \mathrm{C}$ NMR of Solid Methane Hydrates - Structure, Cage Occupancy, and Hydration Number. J. Phys. Chem. 1988, 92, 337339.

20. Lee, Y.; Lee, S.; Park, S.; Kim, Y.; Lee, J. W.; Seo, Y., 2-Propanol as a Co-Guest of Structure II Hydrates in the Presence of Help Gases. J. Phys. Chem. B 2013, 117, 2449-2455.

21. Dec, S. F.; Bowler, K. E.; Stadterman, L. L.; Koh, C. A.; Sloan, E. D., Direct Measure of the Hydration Number of Aqueous Methane. J. Am. Chem. Soc. 2006, 128, 414-415.

22. Gupta, A.; Dec, S. F.; Koh, C. A.; Sloan, E. D., NMR Investigation of Methane Hydrate Dissociation. J. Phys. Chem. C 2007, 111, 2341-2346.

23. Moudrakovski, I. L.; Udachin, K. A.; Alavi, S.; Ratcliffe, C. I.; Ripmeester, J. A., Facilitating Guest Transport in Clathrate Hydrates by Tuning Guest-Host Interactions. J. Chem. Phys. 2015, 142, 074705.

24. Ida, T.; Mizuno, M.; Endo, K., Electronic State of Small and Large Cavities for Methane Hydrate. J. Comput. Chem. 2002, 23, 1071-1075.

25. Siuda, P.; Sadlej, J., Nuclear Magnetic Resonance Parameters for Methane Molecule Trapped in Clathrate Hydrates. J. Phys. Chem. A 2011, 115, 612-619.

26. Siuda, P.; Sadlej, J., Calculations of NMR Properties for sI and sII Clathrate Hydrates of Methane, Ethane and Propane. J. Mol. Model. 2014, 20, 2511.

27. Terleczky, P.; Nyulaszi, L., DFT Study of Possible Lattice Defects in Methane-Hydrate and Their Appearance in ${ }^{13} \mathrm{C}$ NMR Spectra. Chem. Phys. Lett. 2010, 488, 168-172.

28. Liu, Y.; Zhao, J.; Li, F.; Chen, Z., Appropriate Description of Intermolecular Interactions in the Methane Hydrates: An Assessment of DFT Methods. J. Comput. Chem. 2013, 34, 121-131. 
29. Goerigk, L.; Grimme, S., A Thorough Benchmark of Density Functional Methods for General Main Group Thermochemistry, Kinetics, and Noncovalent Interactions. Phys. Chem. Chem. Phys. 2011, 13, 6670-6688.

30. Gutt, C.; Asmussen, B.; Press, W.; Johnson, M. R.; Handa, Y. P.; Tse, J. S., The Structure of Deuterated Methane-Hydrate. J. Chem. Phys. 2000, 113, 4713-4721.

31. Rawn, C. J.; Rondinone, A. J.; Chakoumakos, B. C.; Circone, S.; Stern, L. A.; Kirby, S. H.; Ishii, Y., Neutron Powder Diffraction Studies as a Function of Temperature of Structure II Hydrate Formed from Propane. Can. J. Phys. 2003, 81, 431-438.

32. Udachin, K. A.; Ratcliffe, C. I.; Enright, G. D.; Ripmeester, J. A., Structure H Hydrate: A Single Crystal Diffraction Study of 2,2-Dimethylpentane•5(Xe, $\left.\mathrm{H}_{2} \mathrm{~S}\right) \cdot 34 \mathrm{H}_{2} \mathrm{O}$. Supramol. Chem. 1997, 8, 173-176.

33. Vatamanu, J.; Kusalik, P. G., Unusual Crystalline and Polycrystalline Structures in Methane Hydrates. J. Am. Chem. Soc. 2006, 128, 15588-15589.

34. Lawson, C. L.; Zhang, R. G.; Schevitz, R. W.; Otwinowski, Z.; Joachimiak, A.; Sigler, P. B., Flexibility of the DNA-Binding Domains of Trp Repressor. Proteins: Struc. Funct. Genet. 1988, 3, 18-31.

35. Bernal, J. D.; Fowler, R. H., A Theory of Water and Ionic Solution, with Particular Reference to Hydrogen and Hydroxyl Ions. J. Chem. Phys. 1933, 1, 515.

36. Perdew, J. P.; Burke, K.; Ernzerhof, M., Generalized Gradient Approximation Made Simple. Phys. Rev. Lett. 1996, 77, 3865-3868.

37. Tkatchenko, A.; Scheffler, M., Accurate Molecular Van Der Waals Interactions from Ground-State Electron Density and Free-Atom Reference Data. Phys. Rev. Lett. 2009, 102, 073005.

38. Clark, S. J.; Segall, M. D.; Pickard, C. J.; Hasnip, P. J.; Probert, M. J.; Refson, K.; Payne, M. C., First Principles Methods Using CASTEP. Z. Krist - Cryst. Mater. 2005, 220, 567-570.

39. Pickard, C. J.; Mauri, F., All-Electron Magnetic Response with Pseudopotentials: NMR Chemical Shifts. Phys. Rev. B 2001, 63, 245101.

40. Bonhomme, C.; Gervais, C.; Babonneau, F.; Coelho, C.; Pourpoint, F.; Azais, T.; Ashbrook, S. E.; Griffin, J. M.; Yates, J. R.; Mauri, F.; Pickard, C. J., First-Principles Calculation of NMR Parameters Using the Gauge Including Projector Augmented Wave Method: A Chemist's Point of View. Chem. Rev. 2012, 112, 5733-5779.

41. Bühl, M.; Mourik, T., NMR Spectroscopy: Quantum-Chemical Calculations. Wiley Interdiscip. Rev. Comput. Mol. Sci. 2011, 1, 634-647.

42. Reed, A. E.; Weinhold, F., Natural Localized Molecular-Orbitals. J. Chem. Phys. 1985, 83, 1736-1740.

43. Glendening, E. D.; Landis, C. R.; Weinhold, F., Natural Bond Orbital Methods. Wiley Interdiscip. Rev. Comput. Mol. Sci. 2012, 2, 1-42.

44. Weinhold, F., Natural Bond Orbital Analysis: A Critical Overview of Relationships to Alternative Bonding Perspectives. J. Comput. Chem. 2012, 33, 2363-2379.

45. Liu, Y.; Ojamäe, L., C-C Stretching Raman Spectra and Stabilities of Hydrocarbon Molecules in Natural Gas Hydrates: A Quantum Chemical Study. J. Phys. Chem. A 2014, 118, 11641-11651.

46. Liu, Y.; Ojamäe, L., CH-Stretching Vibrational Trends in Natural Gas Hydrates Studied by QuantumChemical Computations. J. Phys. Chem. C 2015, 119, 17084-17091.

47. Chai, J.-D.; Head-Gordon, M., Long-Range Corrected Hybrid Density Functionals with Damped Atom-Atom Dispersion Corrections. Phys. Chem. Chem. Phys. 2008, 10, 6615-6620.

48. Hehre, W. J.; Ditchfield, R.; Pople, J. A., Self-Consistent Molecular Orbital Methods. XII. Further Extensions of Gaussian Type Basis Sets for User in Molecular Orbital Studies of Organic Molecules. J. Chem. Phys. 1972, 56, 2257-2261.

49. Frisch, M. J.; Trucks, G. W.; Schlegel, H. B.; Scuseria, G. E.; Robb, M. A.; Cheeseman, J. R.; Scalmani, G.; Barone, V.; Mennucci, B.; Petersson, G. A.; et al. Gaussion 09, Revision C.01; Gaussion Inc.: Wallingford: 2011. 50. Kida, M.; Hori, A.; Sakagami, H.; Takeya, S.; Kamata, Y.; Takahashi, N.; Ebinuma, T.; Narita, H., ${ }^{13} \mathrm{C}$ Chemical Shifts of Propane Molecules Encaged in Structure II Clathrate Hydrate. J. Phys. Chem. A 2011, 115, 643-647. 
Table of Contents Image

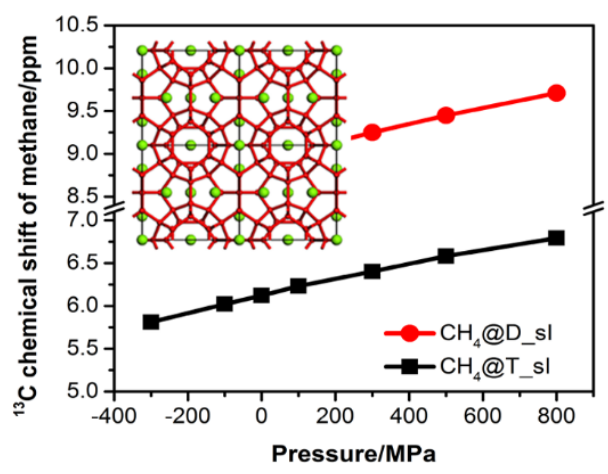

